\title{
Hairy roots of pea mutants with a modified morph leaf type
}

\author{
Olga Timina ${ }^{1^{*}}$, Oleg Timin $^{2}$, and Tat'yana Aleksandrova ${ }^{3}$ \\ ${ }^{1}$ Taras Shevchenko Transdnistrian State University,3300 Tiraspol Transdnistria, Moldova \\ ${ }^{2}$ National Ecology and Natural Resources Scientific Research Institute, 3200 Bendery \\ Transdnistria, Moldova \\ ${ }^{3}$ Transdniestrian Research Institute of Agriculture, 3300 Tiraspol Transdnistria, Moldova
}

\begin{abstract}
In the present study, some pea mutants rich in protein with a modified morph leaf type with af and $t l$ genes were genetically transformed using different strains of Agrobacterium rhizogenes A-4, A-48, 15834. Even though a higher total protein content was obtained with the A-48 strain, maximum of the probable transformants were obtained with the A-4 strain but of transient character. The content of the total protein in hairy roots cultures, depending on the composition of the nutrient media and the growth phase of the culture, has been refined.
\end{abstract}

\section{Introduction}

A promising breeding and technological element now is the genetic transformation using Agrobacterium rhizogenes, as evidenced by the large flow of literature in this direction [1, 2, NASA Astrophysics Data System (ADS)]. The resulting hairy roots, easily subcultured on hormon free media, can be used also in various areas of production, for example, for the manufacture of fast-decomposing to $\mathrm{CO}_{2}$ and $\mathrm{H}_{2} \mathrm{O}$ packaging material [3], in feed production as a valuable protein additive. In pharmacology, the use of hairy roots as a raw material for the production of new types of drugs has every reason to transform into a new industry [4].

The goal of our research is genetic transformation of some pea mutants by TDNA A. rhizogenes with Ri plasmids. Research objectives: receiving hairy roots as a potential forage product; obtaining the pea stock material with new economic and valuable characters.

\section{Material and methods}

*Corresponding author:otimina@mail.ru 


\subsection{Plant material}

The following were the materials used in the study: modified morph leaf type mutants with af and $t l$ genes and usual leaf morph varieties and lines of the Transdniestrian Agricultural Research Institute. Mutants were pre-injected into the in vitro culture to use explants of contrasting protein genotypes. Seeds were disinfected in $0.4 \%$ tetracycline solution for one hour, then 10 minutes (in $10 \%$ sodium hypochlorite solution, 3 times washed with sterile distilled water and planted in flasks on the hormon free half strength media of Murashige and Skug (MS). The flasks were placed in a cultural, working mode: photoperiod $16 / 8, \mathrm{t}=25^{\circ} \mathrm{C}$, humidity $60 \%$, light 4000 lux. The two-week-old plants were used to taking-out the explants. The plants were dissected into different parts like leaf, stems and apexes and evaluated separately for transformation efficiency.

\subsection{Bacterial strains}

Three wild-type agropine strains of $A$. rhizogenes (ATCC15834, A4 and A-48) were used for transformation. All strains were kindly provided by Stepanova A.Y. (Institute of Plant Physiology by K. A. Timiryazev, RAS) for preliminary investigation of transformation procedure. YEB agar medium $(8,5 \mathrm{~g} / \mathrm{L})$ was used for bacterial culture.

\subsection{Infection and co-cultivation of explants}

The daily culture of bacteria was prepared to infect the explants. Wash-out of bacterial culture with approximate optical density (0.6-0.8) at $600 \mathrm{~nm}$ was made by sterile distilled water and used for infecting different explants of pea samples. The surface of the explants was damaged by insulin syringes and then immersed in the bacterial suspension for 20-30 minutes. Explants were washed with sterile water, soaked with sterile filters and placed in Petri dishes for two days on MS hormone free agar medium for co-cultivation. To get rid of the vector, the explants were transplanted to the MC media with $800 \mathrm{mg} / \mathrm{l}$ of cephatoxime, with standing them on this media for 2-5 days. In subsequent passages, antibiotic concentrations were lowered to $100 \mathrm{mg} / \mathrm{L}$.

\subsection{Growth and biochemical indicators}

The formed transplantable plagiotropic roots on a hormone free agar medium were considered as the transformed culture. The mass of the root on the day of cultivation was determined in the dynamics by weighting in fivefold replication. The growth index was calculated as the ratio of the final mass of roots on the agar medium to the original one. The protein definition in plants and hairy roots was carried out by the standard method of Kyedal.

The data obtained were processed by statistically accepted methods.

\section{Results and Discussion}




\subsection{Protein content in pea plants in vitro}

Preliminary screening of the protein content in peas plants grown in vitro under controlled conditions was conducted (Table 1).

Table 1. Protein content in vegetable peas plants in vitro grown on the half-strength of the MS media depending on the genotype

\begin{tabular}{|c|c|c|}
\hline \multirow{2}{*}{ Genotype of the stool plant } & \multicolumn{2}{|c|}{ Total content, \% } \\
\cline { 2 - 3 } & Nitrogen & Protein \\
\hline Acacia-shaped, $t l t l$ & 8.54 & 53.38 \\
\hline Sugar pea, line 89/16 & $9.38-10.36$ & $58.63-64.75$ \\
\hline $\begin{array}{c}\text { Multiple unpaired pinnate leaf type, } \\
\text { af af } t l t l\end{array}$ & $7.84-8.96$ & $49.0-56.0$ \\
\hline Horn, usual morph leaf type & 6.44 & 40.25 \\
\hline Monarch, mustache morph type, af af & 5.32 & 33.25 \\
\hline
\end{tabular}

The results revealed the genotypic component of the total protein content in mutants with different leaf morph type in stable and controlled conditions. The results showed that the genotypes of sugar, acacia and multiple unpaired pinnate leaf type mutants were the most valuable in the order of decreasing.

\subsection{Transformations of explants}

Most of the pea transformation works were done using A.tumefaciens [5] with transformation efficiency from 0.2 to $13.5 \%$. Our results revealed the differentiated ability of bacterial plasmids of the $A$. rhizogenes various strains to integrate and transform the genotypes of vegetable peas. (Table 2).

Table 2. Results of the transformation of different vegetable pea genotypes by three strains of A. rhizogenes, October-December, 2019

\begin{tabular}{|l|c|c|c|c|c|c|c|}
\hline \multirow{2}{*}{ № } & \multirow{6}{*}{$\begin{array}{c}\text { Genotype of the stool } \\
\text { plant }\end{array}$} & \multicolumn{5}{|c|}{ Strain of A. rhizogenes } \\
\cline { 3 - 8 } & & \multicolumn{4}{|c|}{ A-4 } & \multicolumn{3}{|c|}{ A-48 } & \multicolumn{2}{c|}{15834} \\
\cline { 3 - 8 } & & \multicolumn{5}{|c|}{ Transformation results in inducing of, \% } \\
\hline 1 & Sugar pea, line 89/16 & $6 \pm 0.9$ & $31 \pm 0.7$ & $10 \pm 0.8$ & $20 \pm 0.9$ & $0 \pm 0$ & $0 \pm 0$ \\
\hline 2 & $\begin{array}{c}\text { Multiple unpaired } \\
\text { pinnate leaf type, } a f \\
\text { af } t l t l\end{array}$ & $6 \pm 0.7$ & $25 \pm 0.9$ & $0 \pm 0$ & $38 \pm 0.8$ & $0 \pm 0$ & $0 \pm 0$ \\
& $\begin{array}{c}\text { Acacia-shaped, } t l t l \\
3\end{array}$ & $6 \pm 0.7$ & $25 \pm 0.8$ & $8 \pm 0.9$ & $8 \pm 0.7$ & $0 \pm 0$ & $27 \pm 0.7$ \\
\hline 4 & Horn, usual leaf type & $0 \pm 0$ & $0 \pm 0$ & $0 \pm 0$ & $0 \pm 0$ & $0 \pm 0$ & $0 \pm 0$ \\
\hline
\end{tabular}

Taking into account spontaneous shoot formation, the effectiveness of the transformation was greatest in the A-4 strain, but not stable. The universally transformable genotype turned out to be an acacia-shaped mutant. In the case of strain 15384, the root culture was not formed, but shoots were developed and grew, 
although only in acacia-shaped genotype. Only two root cultures were stable. One of which was from the node of the acacia-like mutant, the second has apical origin of the mutant with multiple unpaired pinnate leaves (Figure 1).
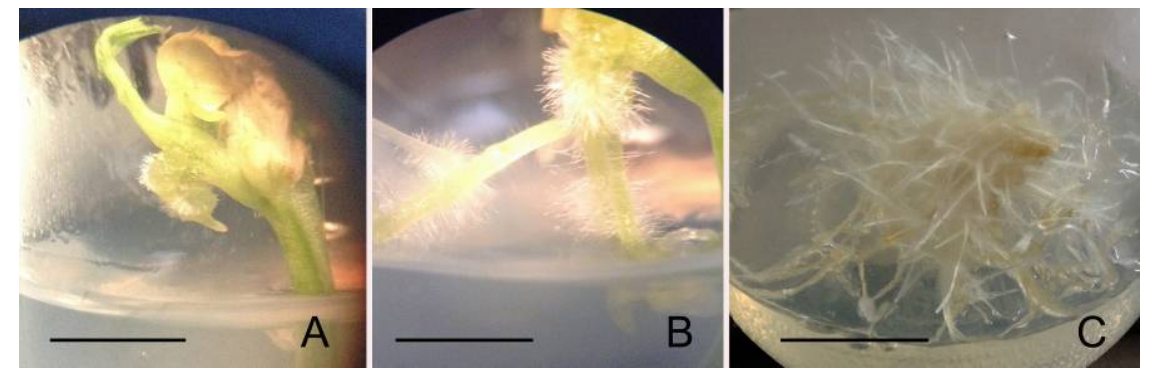

Fig. 1. Hairy roots of pea mutant on a spontaneously formed shoot, derived from the node of multiple unpaired pinnate leaf mutant (strain A-48): A. Initiation of hairy roots. B. 7-day-old hairy roots. C. 30-day-old hairy roots. Bar 150 $\mu \mathrm{m}$ (A, B), $250 \mu \mathrm{m}$ (C).

\subsection{Hairy roots growth dynamics}

Although the growth of culture on the agar media was slow, which coincides with the literary data [6], but the agar media allows to subculture hairy roots once a month. The dynamics of the root mass growth with afaftltl genes on the solid MS media revealed, first, the growth character of culture, and secondly - a clear dependence of growth on the content of sucrose in the media (Table 3).

Table 3. Hairy roots growth dynamics of the multiple unpaired pinnate leaf mutant depending on the content of sucrose in the agar MS hormone free media

\begin{tabular}{|c|c|c|c|c|c|c|}
\hline № & \multirow{2}{*}{$\begin{array}{c}\text { Sucrose } \\
\text { content, \% }\end{array}$} & \multicolumn{3}{|c|}{ The mass of roots, $\mathrm{g}, \mathrm{x} \pm \mathrm{m}$} & \multicolumn{2}{c|}{ Growth index } \\
\cline { 3 - 7 } & & Initial & Day 10 & Day 22 & Day 10 & Day 22 \\
\hline 1 & 0 & 0.166 & $0.212 \pm 0.01$ & $0.218 \pm 0.02$ & $1.3 \pm 0.1$ & $1.4 \pm 0.1$ \\
\hline 2 & 0.5 & 0.150 & $* 0.426 \pm 0.03$ & $* 0.576 \pm 0.06$ & $* 2.5 \pm 0.3$ & $* 3.5 \pm 0.7$ \\
\hline 3 & 1 & 0.166 & $0.376 \pm 0.03$ & $0.602 \pm 0.03$ & $2.5 \pm 0.2$ & $4.0 \pm 0.1$ \\
\hline 4 & 1.5 & 0.182 & $* 0.640 \pm 0.05$ & $* 0.898 \pm 0.04$ & $* 3.9 \pm 0.3$ & $* 5.3 \pm 0.3$ \\
\hline 5 & 2 & 0.182 & $0.570 \pm 0.049$ & $0.893 \pm 0.16$ & $3.1 \pm 0.3$ & $4.9 \pm 0.8$ \\
\hline 6 & 3 & 0.150 & $0.678 \pm 0.03$ & $1.275 \pm 0.14$ & $* 4.6 \pm 0.2$ & $* 8.5 \pm 0.8$ \\
\hline 7 & 4 & 0.150 & $0.567 \pm 0.07$ & $1.150 \pm 0.14$ & $3.8 \pm 0.4$ & $7.7 \pm 0.7$ \\
\hline \multicolumn{7}{|c|}{ Note: *significant differences when comparing options 0-0.5\%, 1-1.5\%, 2-3\%., $\mathrm{P}=0.05$} \\
\hline
\end{tabular}

In the growth cycle, we can distinguish the phase of latent growth (up to eight days), the linear growth phase with the formation of perpendicular roots (duration of three weeks) and the beginning of the deceleration growth phase, depanding jn the content of sucrose. Significant differences in the growth index were noted for the comparable variants $0-0.5 \%, 1-1.5 \%, 2-3 \%$. The variant without the addition of sucrose was also of interest. It is interesting to use this option to deposit culture, perhaps in conjunction with low positive temperatures. 


\subsection{The protein content}

The maximum protein content in hairy root culture was noted in the linear growth phase (Table.4).

Table 4. Biochemical analysis of root culture on the content of total nitrogen and protein depending on the growth phase, composition of the nutrient medium and genotype

\begin{tabular}{|c|c|c|c|c|c|c|}
\hline \multirow{2}{*}{ Genotype } & \multirow{2}{*}{ Media } & \multirow{2}{*}{$\begin{array}{l}\text { Cultiva- } \\
\text { tion, } \\
\text { days }\end{array}$} & \multirow{2}{*}{$\begin{array}{c}\text { Growth } \\
\text { phase }\end{array}$} & \multirow{2}{*}{$\begin{array}{c}\text { Dry } \\
\text { substance, } \\
\%\end{array}$} & \multicolumn{2}{|c|}{ Total content, $\%$} \\
\hline & & & & & Nitrogen & Protein \\
\hline \multirow{4}{*}{ af af tl tl } & $\mathrm{MC}_{20}$ & 27 & Linear & 4.98 & 9.33 & 58.3 \\
\hline & & 33 & \multirow{2}{*}{$\begin{array}{c}\text { Deceler } \\
\text { ation }\end{array}$} & 6.45 & 7.56 & 47.25 \\
\hline & $\mathrm{MC}_{15}$ & 45 & & 5.78 & 7.84 & 49.0 \\
\hline & $\mathrm{WPM}_{20}$ & 31 & \multirow[t]{2}{*}{ Linear } & 6.54 & 5.74 & 35.88 \\
\hline$t l t l$ & $\mathrm{MC}_{20}$ & 27 & & 6.58 & 7.42 & 46.38 \\
\hline
\end{tabular}

The result, although high, can be optimized, judging by the variations of content on different media. One of the main tasks of our research was to obtain transformed plants by rol-genes. The alleged transformants were derived from the nodes of the sugar line and the acacia-shaped mutant. Plants have been successfully adapted in pot culture, have given offspring whose seeds have been sown, and now they are directly evaluated on the main economic and valuable characters. PCR analysis of the offspring of the received transformants and hairy roots cultures is also planned.

\section{Conclusions}

The hairy roots cultures of mutant peas with genes af and $t$ were received with a total protein content of at least $35-58 \%$, depending on the composition of the nutrient media and the growth phase. The offspring of peas plants supposed transformed by rol-genes have been obtained which are evaluated by economic and valuable features.

\section{References}

1. I.N. Kuzovkina, M.Yu. Prokofieva, cell_culture_30_kuzovkina,pdf, 2014

2. B.R. Kuluyev, Biomica, 7, 2 (2015)

3. J. Gueguen, G. Viroben, J. Barbot, Preparation and characterization of films from pea protein isolates, in Proceeding of the 2nd European Conference on Grain Legumes, Copenhagen (1995)

4. T.V. Matveeva, Molecular plant-microbe interactions, 25, 12 (2012)

5. J.E. Grant, P.A. Cooper, Genetic transformation in pea, in Applied Genetics of Leguminosa e Biotechnology (Kluwer Academic Publishers, 2003)

6. H.G. Musin, A.B. Yakupova, E.V. Mikhailova, B.R. Kuluyev, Biotechnology, 13, 2 (2017) 